\title{
Study of Outcome of Open Reduction with Triceps Sparing Method in Paediatric Supracondylar Humerus Fractures
}

\author{
Dr.Ravi Kiran. ${ }^{1}$, Dr.Sreenivasa Reddy ${ }^{2}$, Dr.Reshma Kota ${ }^{3}$, Dr.Saketh Kolla ${ }^{4}$ \\ ${ }^{1}$ Assistant Professor, Osmania Medical College, Hyderabad, ${ }^{2}$ Professor, S.V.Medical College, Tirupathi \\ ${ }^{3}$ Post Graduate, OMC, Hyderabad, ${ }^{4}$ Senior Resident, OMC Hyderabad
}

\begin{abstract}
Supracondylar fracture of humerus in children is the commonest paediatric skeletal injury around the elbow. Peak incidence of this fracture occurs in age group of $6-9$ years. Many treatment modalities are available in the management of Supracondylar fracture of humerus. The aim of this study is to evaluate the of short term results of open reduction using the triceps-sparing approach and Kirschner wire fixation after failed close reduction in Gartland Type III Supracondylar fracture of humerus in children. 30 patients, between age group 1-16 years were included in the study. According to FLYNN'S criteria, results were are analysed. Out of 30 patients $86.66 \%$ patients achieved good to excellent results and $13.33 \%$ showed fair and poor result. $66.66 \%$ of patients had excellent results and $20 \%$ of cases had good results. The total satisfactory results were $86.66 \%$, $10 \%$ of cases had fair results and $3.33 \%$ of cases had poor results. The total unsatisfactory results were $13.3 \%$. Open reduction and $k$-wire fixation without cutting triceps is a choice of treatment for displaced supracondylar fracture of humerus in children because of decreased risk of nerve injuries, vascular injuries and post operative stiffness.
\end{abstract}

Keywords: Supracondylar, Gartland type III, Triceps-sparing, Flynn criteria

\section{Introduction}

Supracondylar fracture of humerus in children is the commonest paediatric skeletal injury around the elbow ${ }^{1}$. Peak incidence of this fracture occurs in age group of $6-9$ years due to various causes mainly ligamentous laxity, active remodelling and anatomical structure of humerus tube to flat transformation at lower end of humerus ${ }^{2,3}$.Many treatment modalities are available in the management of Supracondylar fracture of humerus like

1. Closed reduction and immobilisation in above elbow cast / slab

2. Over head olecranon wing nut traction

3. Closed reduction and percutaneous pinning under image intensifier control

4. Open reduction and pinning ( lateral pin, cross pinning constructs)

5. Lateral external fixator ${ }^{5}$

6. Straight arm skeletal traction ${ }^{6}$.

Supracondylar fracture of humerus is known for complications because of the inherent fracture instability, close vicinity of brachial artery and three major nerves of upper extremity and poor radiographs and poor interpretation of reduction and modality of maintenance of reduction and lastly patient compliance to treatment Supracondylar fracture of humerus is one of the few fractures which when treated well may not bring reputation to the surgeon but which when treated improperly will definitely bring discredit to well reputed surgeon.

\section{Aims and Objectives}

The aim of this study is to evaluate the of short term results of open reduction using the triceps-sparing approach and Kirschner wire fixation after failed close reduction in Gartland Type III Supracondylar fracture of humerus in children.

\section{Materials And Methods \\ Sample size: 30}

Inclusion Criteria:

1)Age of patient 1 to 16 years

2) supra condylar fracture humerus not reduced by closed method (type 3 )

\section{Exclusion Criteria}

1) Age of patient above 16 years. 
2) Patients with intercondylar component

3) Patients not seeking treatment modality according to our protocol

4) Patients presenting with infection at fracture site

5) A fracture associated with vascular damage/neurological damage

\section{Evaluation of patients were done in terms of}

Side of limb injured,time since injury,close or open fracture,puckering of skin at elbow, amount of swelling at elbow,presence or absence of radial pulse,nail bed circulation and signs of compartment syndrome, associated neural injuries_radial, median and ulnar, associated musculoskeletal injuries.

Radiologically evaluation consisted of --- anteroposterior and lateral films initially And after manipulation with or without pinning, Jones view is evaluated. In anteroposterior films -Baumanns angle was measured In lateral films - anterior humeral line, crescent sign and fish tail sign were noted. In Jones view assessment of the coronal alignment of distal fragment was done.

For classification we used Gartland classification with Wilkins modification EXTENSION TYPE and FLEXION TYPES depending upon the sagittal tilt of distal fragment .Both types are further classified into

\section{TYPE I-UNDISPLACED}

TYPE II - DISPLACED WITH INTACT POSTERIOR CORTEX / ANTERIOR CORTEX

TYPE III - DISPLACED WITH NO BONE CONTACT

TYPE III is further classified into two types (Wilkins modification) depending upon the displacement type a)posteromedial

b)posterolateral

\section{The Management Protocol Was}

For type III (completely displaced )--- not reduced by closed methods,. --- open reduction by posterior approach and fixation with K-wire. After fixation elbow is supported with above elbow pop slab or cuff and collar.Indications for open reduction and $\mathrm{K}$ - wire fixation were

1)2 to 3 attempts of failed closed reduction manoeuvring 2)An open fracture

\section{Open Reduction Technique}

We did posterior approach(triceps reflecting) to lower end humerus for the open reduction of fracture .. After open reduction of the fracture, pins are then placed either medially and laterally or two pins are placed laterally, to provide stable fixation. After open reduction, pins may be left in place slightly longer than after closed reduction. Good callus should be observed at the fracture before pin removal, generally 3 to 4 weeks after injury.

Results were graded according to the flynn's criteria as excellent, good, fair and poor results

\section{Excellent:}

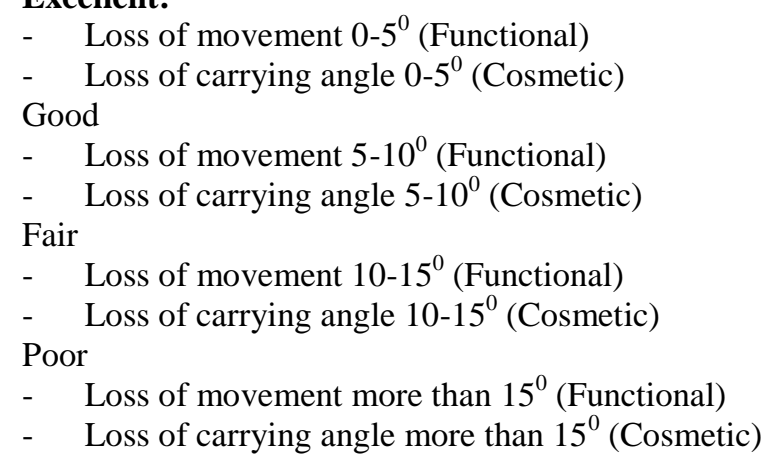

\section{Results}

In present series of 30 patients, Most of the patients are in the age group of $5-8$ years(46.67\%) in our study. Incidence of supracondylar fracture of humerus was more in males $(63.33 \%)$ when compared to females $(36.67 \%)$ in our study. In our study involvement of left side $(66.67 \%)$ is more than right side. We fixed 30 supracondylar fractures of humerus patients. Our preferred construct was cross pinning. We did 1 lateral and 1 medial pinning in 20cases, and 2 lateral pins in 3 cases and 2 lateral pins and 1 medial pin construct in 1 cases. Post operatively,one patient had pin tract infection, 2 patients had developed cubitus varus deformity 
Study of Outcome of Open Reduction with Triceps Sparing Method in Paediatric Supracondylar ..

and one patient had restriction of movements.In $86.67 \%$ cases, change in carrying angle was less than 10 degrees.

Table 1:

\begin{tabular}{|l|l|l|l|l|l|}
\hline \multirow{2}{*}{ Result } & \multicolumn{2}{|l|}{ according to loss of range of motion } & \multicolumn{2}{l|}{ According to loss of carrying angle } & Average percentage \\
\cline { 2 - 6 } & No. of patient & $\%$ & No. of patient & Percentage & \\
\hline Excellent & 20 & $66.66 \%$ & 20 & $66.66 \%$ & $66.66 \%$ \\
\hline Good & 6 & $20 \%$ & 6 & $20 \%$ & $20 \%$ \\
\hline Fair & 3 & $10 \%$ & 3 & $10 \%$ & $10 \%$ \\
\hline Poor & 1 & $3.33 \%$ & 1 & $3.33 \%$ & $3.33 \%$ \\
\hline
\end{tabular}

According to FLYNN'S criteria ${ }^{7}$ results of our study are analysed. In our study, out of 30 patients $86.66 \%$ patients were good to excellent and $13.33 \%$ showed fair and poor result.66.66\% of patients had excellent results and $20 \%$ of cases had good results. The total satisfactory results were $86.66 \%, 10 \%$ of cases had fair results and $3.33 \%$ of cases had poor results. The total unsatisfactory results were $13.3 \%$.Poor and fair results were because of initially they had prior treatment before admission in the form of massage and manipulation and secondaryily due to difficulty in reduction and fixation of the fragments in unsatisfactory position.

\section{Discussion}

\section{Age Distribution}

Musa et al $^{10}$ conducted a prospective study based on 30 cases with type III Gartland fracture managed by crossed percutaneous pinning over a period of two years. Age group range was 2 to 13 years with a mean age of 7.06 years. Charles A Rockwood observed that the peak incidence of supracondylar fracture of humerus in children is in the later part of first decade of life.

In the present study, the average age is 7 years ( range 2 -- 15 years ) and the most common age group affected was between $5-8$ years $(46.67 \%)$.

\section{Sex Distribution}

Pirone A M et al in their study of 230 patients with supracondylar fracture of humerus showed that boys (119) were affected more than girls

Robert D Ambrosia in his series found an incidence of supracondylar fracture of humerus in male child is $63 \%$ and female child is $37 \%$. females.

In our study, the incidence of supracondylar fracture of humerus is $63.33 \%$ in male and $36.67 \%$ in

\section{Side Involvement}

Robert D Ambrosia found involvement of left elbow was $64 \%$ and involvement of right side was 36 $\%$ among his cases of supracondylar fracture of humerus in children. Ahamad et al in their study of supracondylar fracture of humerus in children showed the predominance of left side involvement.In the present study left side was involved in $67 \%$ and right side $33 \%$ cases. incidence of side involvement in the present study is consistent with the above series.

\section{Fracture Type Incidence ( Gartland Classification With Wilkins Modification )}

Pirone A H et al (1988) studied 230 cases of displaced supracondylar fracture of humerus and observed that $137(62 \%)$ cases were type III fractures and 83 (36\%) were type II .in type III fractures 94 were with posteriomedial displacement ,22 with posterolateral displacement and 21 with direct posterior displacement. Mehlman et al during their study of operative treatment of supracondylar fracture of humerus in children found that according to Gartland's classification ,77.4\%were type III fractures and 18.3\% were type II fractures On comparison, in the present study of 30 patients , $4(13.33 \%)$ were type I , 8(26.66\%) were type II and $18(60 \%)$ were type III fractures.

\section{Complications Pin Tract Infection}

Pirone A H et al (1988) studied 230 cases of displaced supracondylar fracture of humerus and observed that out of 78 cases treated with closed reduction and percutaneous pinning 2 cases had pin tract infection Cramer K E in his retrospective review of 29 children with supracondylar fracture of humerus in children treated with closed reduction and percutaneous pinning and open reduction and percutaneous pinning 1 patient in closed reduction and percutaneous pinning group out of 15 cases showed superficial pin tract infection 
Lejman $\mathrm{T}$ et al showed no case of pin tract infection in 20 cases of supracondylar fracture of humerus cases treated with closed reduction and percutaneous pinning In our study 1 patient showed evidence of pin tract infection in 30 cases treated with open reduction and pinning.

\section{Cubitus Varus}

Topping et al showed incidence of cubitus varus in one patient(4.3\%) out of 43 cases treated with closed reduction and percutaneous pinning.

Kennedy observed 2 cases with cubitus varus deformity among 32 cases of displaced supracondylar fracture of humerus in children.

In the present study, two patients $(6.67 \%)$ developed cubitus varus. This deformity is seen with one patient in open reduction and percutaneous pinning group .

\section{Proximal Migration Of Wire}

Pirone A M et al observed migration of one lateral pin out of 96 cases treated with closed reduction and percutaneous pinning.

In our study ,in no case we saw this complication because in all pinning cases we bent k-wires outside the skin after application.

\section{Results}

In our study, results are evaluated according to Flynn"s criteria which is based on change in carrying angle and loss of movement after treatment.

Franke et al in study of 106 patients with displaced supracondylar fracture of humerus treated with closed reduction and percutaneous pinning showed $85.7 \%$ good to excellent results with $10.7 \%$ satisfactory results and $4.6 \%$ with unsatisfactory results.

Ababneh et al in his retrospective study of 135 patients with displaced supracondylar fracture of humerus treated with three different methods, results of closed reduction and percutaneous pinning were superior, with excellent and good results in $87 \%$ patients and poor results in $8 \%$ patients.

Bopanai and Rakesh sharma et al studied 54 cases of supracondylar fracture of humerus and found that $80 \%$ good results and $20 \%$ unsatisfactory results in open reduction and internal fixation group compared to $44 \%$ unsatisfactory results in closed reduction and percutaneous pinning group.

In our study, out of 30 patients $86.66 \%$ patients were good to excellent and $13.33 \%$ showed fair and poor results.

\section{Conclusion}

Open reduction and k-wire fixation without cutting triceps is a choice of treatment for displaced supracondylar fracture of huemrus in children because of decreased risk of nerve injuries, vascular injuries and post operative stiffness. Late complication like cubitus varus deformity can be avoided by open reduction and kwire fixation,as perfect anatomical reductioncan be achieved as compared to closed reduction and casting in displaced fractures.

\section{References}

[1]. Wilson et al, fracture and dislocation in region of elbow ; surg gynaec obstet 1933: $56 ; 335$ - 59.

[2]. Henrikson et al supracondylar fracture of humerus ; Acta Chir scand ( suppl) 1966; 36: 9—12

[3]. Abraham E et al : Experimental hyperextension of supracondylar fracture of humerus in monkies clinical orthopaedics ; 1982 ; 171 : $309-318$.

[4]. Adam F. et al : Genuine works of Hippocrates ( translated from greek ) Baltimore, wiliams and Wilkins ,1939.

[5]. Teddy slongo et al lateral external fixation - a new technique for displaced unrreducible supracondylar fracture of humerus in children JBJS ,Am,Aug $2008: 90: 1690-1697$.

[6]. A. Gadgil et al Straight-arm Traction for supracondylar fracture of humerus Fractures of the Humerus in Children Journal of Bone \& Joint Surgery: British Volume Vol.: 87-B, No.: 1, January, 12005 [Page 82-87]

[7]. Faith eksioglu et al comparison of closed reduction and percutaneous pinning Pinning Procedure with Open Reduction-internal Fixation in the Surgical Treatment ofChildren Displaced supracondylar fracture of humerus Joint Diseases and Related surgery Vol.: 11, No.: 2, 2000 [Page 173-178]

[8]. Flynn J C et al ; Blind pinning of displaced supracondylar fractures of the humerus in children. Sixteen years experience with long term follow up J bone and joint surgery Am ,1974 56: 263-272

[9]. Zionts et alClinical Orthopaedics and Related Research Vol.: 467, No.: 8, August 2009 [Page 2007-2010]

[10]. Musa et al Displaced Supracondylar Humeral Fractures in Children- Treatment Outcomes Following Closed Reduction and Percutaneous Pinning Internet Journal of Orthopedic Surgery Vol.: 17, No.: 1, 2010

[11]. M. D. Mckee et al Functional Outcome after Open supracondylar fracture of humerus : The Effect of the Surgical Approach Journal of Bone \& Joint Surgery: British Volume Vol.: 82-B, No.: 5, July 2000 [Page 646-651]

[12]. Samir P Pilankar et al Novel Technique of Pin Passage and Construct in the Treatment of Type 3supracondylar fracture Humerus in Children Bombay Hospital Journal Vol.: 48, No.: 2, April 2006.

[13]. M. Sibinski et al early Versus Delayed treatment of Extension Type-3 Supracondylar Fractures of the Humerus in Children Journal of Bone \& Joint urgery: British Volume Vol.: 88-B, No.:3, March, 12006 [Page 380-381] 
[14]. James R. Lewis et al Changing the Management from Olecranon Screw Traction to Percutaneous Wiring for Displaced supracondylar Fractures of the Humerus in Children. a Justified Decision European Journal of Trauma and Emergency Surgery Vol.: 33, No.: 3, June 2007 [Page 256-261]

[15]. Matsuzaki et al Treatment of supracondylar fracture of humerus in Children by Skeletal Traction in a Brace Journal of Bone \& Joint Surgery: British Volume Vol.: 86-B, No.: 2, March 2004 [Page 232-238]

[16]. Antoine de Gheldere; et al results of closed reduction and cast immobilisation in supracondylar fracture of humerus in children Indian Journal of Orthopaedics Vol.: 44, No.: 1, January, 12010 [Page 89-94].

[17]. P. J. Walmsley et al Delay Increases the Need for Open Reduction of Type- III supracondylar fracture of humerus , Journal of Bone \& Joint Surgery: British Volume Vol.: 88-B, No.: 4, April, 12006 [Page 528-530

[18]. F. Ghasemzadeh et al Absence of Radial Pulse in Displaced supracondylar fracture of humerus in Children Archives of Iranian Medicine Vol.: 5, No.: 1, January 2002

[19]. Chang-Wug Oh et al Displaced supracondylar fracture of humerus in Children: Results of Open Reduction Versus Closed Reduction Journal of Orthopaedic Science Vol.: 8, No.: 2, March 2003 [Page 137-141]

[20]. Ritabh Kumar et al Medial approach for operative treatment of he widely displaced supracondylar fractures of the humerus in children Journal of Orthopaedic Surgery 2000, 8(2): 13-18

[21]. Andreas Hoyer et $\mathrm{al}^{21}$ Treatment of supracondylar fracture of humerus by skeletal traction in an abduction splint JBJS Am 1952; $34: 623-637$

[22]. De Boeck $\mathrm{H}$ et al, Supracondylar elbow fractures with impaction of the medial condyle in children. Journal of Pediatric Orthopedics. 15:444,1995

[23]. Fowler et al displaced supracondylar fracture of humerus in children; JBJS (Br) 1974 56;490--500.

[24]. Topping et al,clinical evaluation of crossed pin versus lateral pin fixation in displaced supracondylar humerus fractures $\mathrm{J}$ PEDIATRIC ORTHOP 1995; 15;435-439.

[25]. Badhe et al olecranon screw traction for displaced supracondylar fracture of humerus in childrens inury 1998;29;457-460.

[26]. Archibeck MJ et al Brachialis muscle entrapment in displaced upracondylar humerus fractures: a technique of closed reduction and report of initial results. J Pediatr Orthop 17:298, 1997.

[27]. Battaglia TC, Armstrong DG, Schwend RM. Factors affecting forearm compartment pressures in children with supracondylar fractures of the humerus. Journal of Pediatric Orthopedics 22:431,2002.

[28]. Campbell CC, Waters PM, Emans JB, Kasser JR, Millis MB.Neurovascular injury and displacement in type III supracondylar humerus fractures. J Pediatr Orthop 15:47,1995.

[29]. Cheng J, Lam T, Shen W. Closed reduction and percutaneous pinning for type III displaced supracondylar fractures of the humerus in children. J Orthop Trauma: 9:511,1995.

[30]. Cheng JC, Lam TP, Maffulli N. Epidemiological features of supracondylar fractures of the humerus in Chinese children. Journal of Pediatric Orthopaedics, Part B.10:63,2001.

[31]. Cramer KE, Devito DP, Green NE. Comparison of closed reduction and percutaneous pinning versus open reduction and percutaneous pinning in displaced supracondylar fractures of the humerus in children. J Orthop Trauma 6:407,1992

[32]. Bellemore, M. C., I. R. Barrett, et al. "Supracondylar osteotomy of thehumerus for correction of cubitus varus." Journal of Bone \& Joint Surgery - British Volume. 66B: 566, 1984

[33]. Beslikas, T. A., J. M. Kirkos, et al. "Supracondylar humeral osteotomy in children with severe posttraumatic cubitus varus deformity." Acta Orthopaedica Belgica. 65: 65, 1999.

[34]. Copley LA, Dormans JP, Davidson RS. Vascular injuries and their sequelae in pediatric supracondylar humeral fractures: toward a goal of prevention. Journal of Pediatric Orthopedics. 16:99, 1996.

[35]. Culp RW, Osterman AL, Davidson RS, Skirven T, Bora FW, Jr. Neural injuries associated with supracondylar fractures of the humerus in children. JourBone \& Joint Surg. 72A:1211, 1990

[36]. Hillard spencer, et al; prospective longitudinal evaluation of elbow motion following paediatric supracondylar fracture of humerus JBJS (Am) Apr 2010,92; 904-910.

[37]. Gray's anatomy, students edition : page no- 669-682

[38]. Rockwood Jr C.A., Kaye . E. Wilkins, Richards E. Kind. Fracture in children. $3^{\text {rd }}$ edition, published by Lippincott company Philadelphia, Vol. 3, 508-615, Vol-1, 739-51

[39]. Wadsworth. Thomas G: The elbow. Published by Churchill living stone, 1982, 173-84

[40]. Tachdjian. Mihran O; Paediatric Orthopaedics. $2^{\text {nd }}$ edition, Vol.4, W. B. Saunders Company, 1990, 3058-92

[41]. Kramhoft M., I.L Keller and S. Solgaard; Displaced supracondylar Fractures of the humerus in children. Clinical Orthopaedics and related research, No. 221, August 1987, -15-20

[42]. Kurer. K.H.J and M.W. Regan: Completely displaced supracondylar fracture of the humerus in children. A review of 1708 comparable cases. Clinical orthopaedics and related research No. 256, July 1990, 205-12

[43]. Pirone A.M., A. M., H.K. Graham, J. I. Krajbich; Management of displaced extension type supracondylar fractures of the humerus in children, J.B.J.S, Vol. 70-A, No.5, June 1988, 641-49

[44]. Deva Kumaran K.C.: Displaced supracondylar freactures of humerus in children by primary open reduction and fixation with kirscher wire. Indian journal of Orthopaedic, vol. 19 No.1, January 1985, 20-25

[45]. Wilkins Kaye E.: The operative managemtn of supracondylar fractures. Orthopaedic clinics of North America, Vol 21, No. 2,April 1990, 269-88

[46]. Worlock Peter: Supracondylar fractures of the humerus- Assessment of cubtus varus by the Baumann's angle, J.B.J.S., Vol. 68-B, No.5, November 1986m 755-57 